\title{
As dimensões do cuidado em uma unidade de queimados: um estudo etnográfico*
}

\author{
THE DIMENSIONS OF THE CARE INABURN UNIT: AN ETHNOGRAPHIC STUDY \\ LAS DIMENSIONES DEL CUIDADO EN UNA UNIDAD DE QUEMADOS: UN ESTUDIO ETNOGRÁFICO
}

\author{
Elaine Carvalho Fernandes Braga Costa ${ }^{1}$,Lídia Aparecida Rossi
}

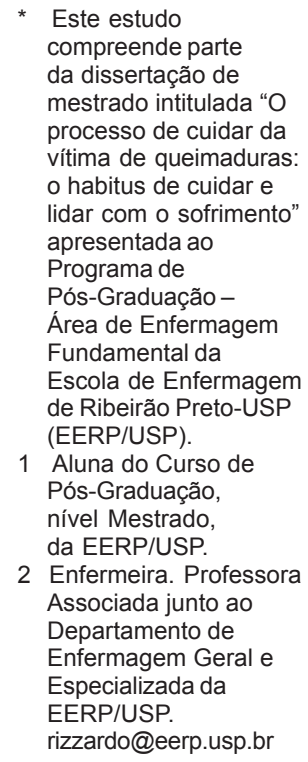

1 Aluna do Curso de Pós-Graduação, nível Mestrado, da EERP/USP.

2 Enfermeira. Professora Associada junto ao Departamento de Enfermagem Geral e Especializada da EERP/USP. rizzardo@eerp.usp.br

\begin{abstract}
RESUMO
Este estudo etnográfico teve como objetivo compreender as perspectivas culturais dos profissionais de enfermagem que atuam em uma Unidade de Queimados sobre cuidado do paciente vitima de queimaduras. Os dados foram coletados por meio de observação e entrevistas e interpretados de acordo com a perspectiva de Bourdieu, que utiliza os conceitos de habitus e campo para compreender os comportamentos que expressam o que está interiorizado pelas pessoas que fazem parte de um grupo social. Para desempenhar o cuidado, os profissionais agem de acordo com formas que já interiorizaram, como sofrer junto, ser firme e, ao mesmo tempo, atencioso e carinhoso.
\end{abstract}

\section{PALAVRAS-CHAVE}

Queimaduras.

\begin{abstract}
This aim of this ethnographic study is to understand a nursing staff's cultural perspectives throughout the care of a burned client in a burn unit. Data were collected through observation and interviews and interpreted in accordance with Bourdieu's perspective, that uses the habitus concepts and field to understand the behaviors that express what is internalized by people that belong to a social group. To carry out these dimensions of care, the professionals act in agreement with the forms that already internalized, and they expressed in their depositions: to suffer together, to act firmly, and at the same time, to be kind and affectionate.
\end{abstract}

\section{KEYWORDS}

Burns.

Culture.

\section{RESUMEN}

Este estudio etnográfico tuvo como objetivo comprender las perspectivas culturales de profesionales de enfermería, que actúan en una Unidad de Quemados, sobre el cuidado del cliente que sufrió quemaduras. Los datos fueron obtenidos por medio de observación y entrevistas e interpretados de acuerdo con la perspectiva de Bourdieu, que utiliza los conceptos de habitus y campo para comprender los comportamientos que expresan lo interiorizado por personas que hacen parte de un grupo social. Para desempeñar el cuidado, los profesionales actúan de acuerdo a formas ya interiorizadas tales como: sufrir junto, ser firme y al mismo tiempo atento $y$ cariñoso.

\section{PALABRAS-CLAVE}

Quemados.

Cultura.

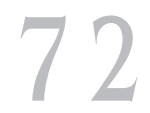

Rev Esc Enferm USP 2003; 37(3): 72-81. 


\section{INTRODUÇÃO}

O trabalho em unidades especializadas, que envolve a assistência ao paciente em estado crítico, tem sido considerado estressante, principalmente quando essa assistência está dirigida ao paciente que sofreu queimaduras ${ }^{(1)}$.

Na nossa prática clínica em uma Unidade de queimados, observamos diferentes reações dos profissionais de enfermagem frente ao cuidado da vítima de queimaduras. As reações da equipe são as mais diversas, desde o comportamento carinhoso até, muitas vezes, rígido e firme. Vários fatores podem determinar essas reações. Entre esses fatores, destacamos a história do acidente que provocou o trauma e todas as situações que envolvem o cuidado de enfermagem a esses pacientes.

Em relação à história do trauma, as queimaduras provocadas por tentativa de suicídio são, muitas vezes, consideradas como comportamentos reprováveis em nossa cultura, e podem provocar reações que se caracterizam por atitudes de rejeição por parte dos profissionais.

Assistir ao paciente que sofreu queimaduras, tendo como agravante a tentativa de suicídio, é muito difícil para a equipe multiprofissional, que não se sente preparada para este cuidado. Freqüentemente, a equipe não se sente disposta a lidar com seus próprios tabus e preconceitos que, "dificultam o estabelecimento de interações compreensivas com o paciente", resultando em estresse, ansiedade e impaciência ${ }^{(2)}$.

Os acidentes domésticos, que ocorrem com mais freqüência e atingem em sua maioria crianças ${ }^{(3)}$, também envolvem situações que provocam reações na equipe de enfermagem. Freqüentemente, o profissional enfrenta dificuldades no relacionamento com crianças que sofreram queimaduras e com seus familiares, os quais expressam sentimentos de culpa e responsabilidade pelo acidente que, muitas vezes, poderia ter sido evitado.

Além dos aspectos relacionados com a história do acidente, a convivência com pacientes que permanecem internados por um longo período e que são sujeitos a inúmeros procedimentos dolorosos é bastante complexa para a equipe. Diariamente, o paciente que sofreu queimaduras é submetido à higiene corporal e à limpeza da área atingida pela queimadura; é submetido ao curativo e estimulado a realizar exercícios fisioterápicos. Procedimentos esses que geram dor.

Em um estudo desenvolvido no Centro de Queimados do Hospital de New York foram analisadas as atitudes da equipe de enfermagem frente à dor do paciente que sofreu queimaduras. Neste estudo concluiu-se que o profissional está ciente da presença da dor e, muitas vezes, da sua participação em causá-la e que os pacientes seriam mais bem atendidos se os enfermeiros adquirissem maiores conhecimentos sobre analgesia ${ }^{(4)}$. Entretanto, a própria decisão de dar ou não o medicamento é influenciada por aspectos culturais $^{(5)}$.

Os enfermeiros têm um papel preponderante na avaliação da dor e tem conhecimento sobre as possibilidades terapêuticas, podendo influenciar a escolha da analgesia do paciente. São os profissionais de enfermagem que presenciam a queixa de dor, avaliam a sua manifestação e agem com a finalidade de dar alívio ao paciente ${ }^{(6)}$.

O conflito entre membros da equipe, a sobrecarga de trabalho e o tratamento injusto pelos superiores foram descritos como causas de estresse num levantamento realizado na Unidade de Queimados do Hospital de Tygerberg, África do Sul ${ }^{(7)}$. Neste estudo, foram analisados os agentes estressores no ambiente hospitalar e concluiu-se que programas de apoio são importantes para criar estratégias de enfrentamento.

Tanto os fatores que desencadeiam as reações dos profissionais frente ao cuidado de enfermagem ao paciente que sofreu queimaduras como as suas formas de enfrentamento dependem de significados culturais aprendidos ao longo da vida dessas pessoas.

Assim, este estudo teve como objetivo compreender os significados da atuação de um grupo de profissionais de enfermagem em uma Unidade de Queimados, no que diz respeito ao processo de cuidar do paciente que sofreu queimaduras, com a finalidade de fornecer subsídios para a elaboração de programas de apoio à equipe de enfermagem.
As dimensões do cuidado em uma unidade de queimados: um estudo etnográfico 
Elaine Carvalho F.B.Costa Lídia Aparecida Rossi

\section{REFERENCIAL TEÓRICO- METODOLÓGICO}

Foi utilizada a abordagem etnográfica como metodologia para desenvolvimento desta pesquisa e, na interpretação dos dados, a perspectiva de Pierre Bourdieu ${ }^{(8)}$ descrita a seguir.

Pierre Bourdieu utiliza dois conceitos fundamentais: a noção de habitus e de campo. $\mathrm{O}$ conceito de habitus, utilizado para designar a cultura de um grupo social, refere-se a

um sistema de esquemas interiorizados que permite engendrar todos os pensamentos, percepções e ações características de uma cultura...(9).

Cultura é uma construção que se inscreve na história das relações dos indivíduos de um grupo social ${ }^{(10)}$.

O conceito de campo surge quando, nessa perspectiva, recusa-se qualquer interpretação individual interna e externa para explicar o comportamento humano. Assim, recusa-se também a tentativa de explicação do comportamento humano a partir do próprio comportamento humano. O campo se forma a partir de interesses específicos e em comum e se rege por regras e leis de funcionamento. As práticas são gradativamente sedimentadas, tornando-se "naturais". Os agentes são aqueles que estão dispostos a aceitar essas leis e a estruturá-las ${ }^{(8)}$.

Há uma hierarquia interna no campo: os dominantes e os dominados. O campo funciona considerando a complexidade das posições e da tomada das posições, pois é um espaço onde se manifestam relações de poder. Há o espaço para mudanças quando o agente, a partir da sua profunda interiorização do habitus, rompe com esse habitus e ameaça o poder dos dominantes. Assim, há espaço para que mudanças aconteçam. Esse momento é esperado, porém o campo é conservador, pois mesmo com uma revolução interna, ele não se dissolve ${ }^{(9)}$.

Nesta perspectiva, o cuidado de enfermagem é uma prática social que pressupõe relações sociais que, por sua vez, estabelecem e constituem o habitus. Essas práticas são guiadas e reproduzidas pelo habitus e obedecem a uma ordem pré-estabelecida. A maneira como se cuida está definida. Essa perspectiva auxilia a compreensão e percepção de como este cuidado está determinado e como pode ser aperfeiçoado.

Os dados qualitativos são ricas descrições dos diversos contextos sociais, podendo preservar a seqüência cronológica e relacionar eventos às suas conseqüências, ajudando os pesquisadores a ir além do seu conceito inicial, gerando e revisando estruturas de trabalho ${ }^{(11)}$. Os significados e as intenções humanas funcionam dentro de estruturas sociais que são invisíveis, porém reais. Em outras palavras, fenômenos sociais como, por exemplo, a linguagem, as decisões, os conflitos e hierarquias exercem fortes influências nas atividades humanas, ou seja, as pessoas são influenciadas mutuamente. Nesse sentido, a opção metodológica, centrada no método etnográfico, possibilitou entender a temática estudada considerando a perspectiva dos participantes do estudo.

A escolha da abordagem etnográfica na condução deste estudo, se justifica pela sua adequação à exploração do cotidiano dos profissionais de enfermagem, de suas atividades, comportamentos e emoções.

A situação social selecionada para o desenvolvimento deste estudo focalizou o cuidado realizado pelos profissionais de enfermagem aos pacientes que sofreram queimaduras, internados na Unidade de Queimados do Hospital das Clínicas da Faculdade de Medicina de Ribeirão Preto (HCFMRP). Esta unidade possui oito leitos, admitindo pacientes adultos e crianças. A equipe de enfermagem é composta por seis enfermeiros, uma técnica de enfermagem e quinze auxiliares de enfermagem.

Antes de iniciar o desenvolvimento desse estudo, o projeto foi aprovado pelo Comitê de Ética em Pesquisa do HCFMRP.

Para a coleta de dados, foram realizadas observação participante e entrevistas semiestruturadas. Foram observadas as atividades diárias realizadas pelos profissionais de enfermagem no trabalho da Unidade de Queimados, buscando focalizar os aspectos culturais que envolvem o cuidado ao paciente que sofreu queimaduras.

As observações foram registradas em um diário de campo e as entrevistas foram realizadas após a explicação do objetivo do traba- 
lho aos informantes, que assinaram o termo de consentimento e autorizaram a gravação das entrevistas.

Os participantes deste estudo foram os membros da equipe de enfermagem que atuam nesta Unidade, responsáveis pela assistência prestada ao paciente que sofreu queimaduras e que demonstraram interesse em falar sobre o tema estudado.

Foram entrevistados formalmente dez participantes, sendo três enfermeiros, um técnico de enfermagem e seis auxiliares de enfermagem. Os outros profissionais de enfermagem dessa unidade, num total de nove auxiliares e três enfermeiros participaram das entrevistas informais realizadas no decorrer das observações e, também, tiveram suas atividades observadas durante o trabalho de campo. Utilizou-se como critério para interromper a coleta de dados, a saturação dos dados ${ }^{(12)}$. Considerou-se não somente a repetição das informações nas entrevistas formais, mas também a confirmação das informações obtidas nas entrevistas pelas observações.

Para garantir ao entrevistado a liberdade para discorrer sobre o tema proposto, as entrevistas formais foram realizadas individualmente. Optou-se por entrevistas semiestruturadas, orientadas, inicialmente, por três questões principais:

Para você, o que é cuidar do paciente vítima de queimaduras? O que é trabalhar na Unidade de Queimados? Como você lida com as situações que se apresentam no seu dia-a-dia no trabalho desta unidade?

Para o registro dos dados obtidos pela observação participante, foram utilizados papel e lápis; e gravador, para os dados obtidos mediante entrevistas. Os dados foram registrados no programa de computador Ethnograph v 5.0. Este programa tem a finalidade de armazenar os dados coletados de forma organizada, com ferramentas que fornecem detalhes para uma análise etnográfica.

No processo de análise, consideramos as seguintes fases inter-relacionadas, a saber, redução dos dados, apresentação dos dados, e delineamento das conclusões e verificação ${ }^{(11)}$. O processo de redução dos dados foi iniciado com o desenvolvimento do estudo. Esta fase se refere ao processo de seleção, abstração e transformação dos dados; ocorre continuamente durante o processo de co- leta de dados. É por meio desse processo que o foco da coleta de dados é definido e que aspectos importantes da investigação são identificados, ou seja, novas questões e aspectos a serem observados são incluídos no trabalho de campo ${ }^{(11)}$. É sempre importante lembrar que em estudos etnográficos, o processo de coleta e análise dos dados é simultâneo. Na medida em que os dados eram coletados e organizados, mediante a realização de leitura cuidadosa das informações, procuramos extrair as idéias que se constituíam em conceitos importantes e as situações que chamavam a atenção, considerando-se os objetivos do estudo. Com o desenvolvimento desse processo, foram identificados os códigos (unidades de significado), ou seja, todas as informações contidas no texto foram identificadas e rotuladas. Cada uma dessas unidades foi explicada e conceituada. A partir desses primeiros códigos, os dados foram novamente analisados com o objetivo de verificar a freqüência em que essas unidades de significado eram apresentadas e construir as categorias. Após esse processo, os códigos similares foram agrupados em categorias ${ }^{(11,13)}$. Esses códigos e categorias foram apresentados em um quadro para que pudessem ser mais bem observados (apresentação dos dados). Foram identificadas três categorias, entretanto, nesta publicação, será abordada apenas uma que sintetiza o significado cultural da atuação na perspectiva dos profissionais de enfermagem da Unidade de Queimados em estudo, apresentada a seguir: Cuidado como habitus: a dimensão física $e$ emocional

\section{CUIDADO COMO HABITUS: A DIMENSÃO FÍSICA E EMOCIONAL}

Ao abordar o significado da atuação na Unidade de Queimados, os profissionais focalizaram o cuidado físico e as dificuldades em lidar com o sofrimento. Constatando-se assim, duas dimensões do cuidado: a física e a emocional.

Os depoimentos dos profissionais mostram o que está interiorizado por eles no que se refere à reação do paciente durante o cuidado que deve ser feito, ou seja, o cuidado físico. Observa-se que a dimensão física segue um modelo já estabelecido: aquilo que deve ser feito, um cuidado que é realizado diariamente. O banho e o curativo são procedimentos que caracterizam o trabalho na Unidade de Queimados. Por essa razão, foram os
As dimensões do cuidado em uma unidade de queimados: um estudo etnográfico 
Elaine Carvalho F.B.Costa Lídia Aparecida Rossi cuidados mais enfocados pelos profissionais de enfermagem neste estudo e também porque esses procedimentos visam à resolução de um problema que se apresenta como prioridade na perspectiva dos profissionais: a queimadura.

Há um modelo interiorizado pelos profissionais sobre como esses procedimentos devem ser realizados, entretanto, eles são altamente dolorosos e provocam reações nos pacientes e na própria equipe.

A dor da queimadura está geralmente relacionada com atividades específicas tais como limpeza da ferida, desbridamento, mudança de curativos e fisioterapia(14).

As reações dos pacientes, que se constituem em manifestações de dor, provocam também reações nos profissionais, que lançam mão de recursos para enfrentar a situação, como, por exemplo, ser firme com o paciente. Apesar disso, o cuidado deverá ser realizado. O depoimento a seguir exemplifica essa situação:

Pedro: cada paciente se comporta de uma forma, diante das dores que eles estão passando, mas têm algumas coisas alguns comportamentos que são repetitivos que é sempre fugir da dor, fugir da situação então por isso que a gente tem que ser bastante firme com eles... (Auxiliar de enfermagem)

"Cada paciente se comporta de uma forma" como afirmou o profissional, entretanto, não são muitas as variações sobre como realizar o cuidado, que tem que ser feito.

De acordo com Forest ${ }^{(15)}$, o cuidado envolve "ser firme" e "ensinar". Esses aspectos do cuidado têm o objetivo de ajudar o paciente a desenvolver seu conhecimento pessoal e sua independência ${ }^{(15)}$. Na perspectiva do profissional, "ser firme" engloba: dizer não ao paciente, dar alguma informação que ele possa não querer ouvir, fazer procedimentos necessários mesmo que ele não queira aceitar e agir de acordo com o seu bem estar e interesse. Como mostra a afirmação a seguir, é preciso firmeza para realizar o "procedimento correto":

Pedro: a gente tem que ser firme se não a gente não consegue cuidar, não consegue fazer o procedimento correto. Então, mas a gente tem procurado melhorar, amenizar as dores, fazer o procedimento da melhor maneira, de forma que ele sofra menos. (Auxiliar de enfermagem)
$O$ fazer procedimento correto é fazer o que deve ser feito, com ajustes para amenizar as dores e "fazer de uma melhor maneira" se refere a uma tentativa de amenizar o problema, fazer o que deve ser feito de uma forma que o paciente sofra menos.

\section{Mariana: Tem que ser dura, mas tem que ter jeito para falar porque se não falar direito, assim com educação, respeitando a dor dela. Lógico, a gente sabe que vai doer, mas tem que limpar. Se limpar, vai dar um resultado melhor. Então, eu acho que a comunicação ajuda muito no trata- mento. Ajuda bastante como você fala com o paciente. (Auxiliar de enfermagem)}

Uma maneira para melhorar o cuidado é explorar a experiência do paciente durante $\mathrm{o}$ tratamento. Fortalecer a habilidade dele para suportar esse tratamento aliviará seu sofrimento. Aliviar o sofrimento é a principal responsabilidade da enfermagem. Os enfermeiros são responsáveis pelo completo cuidado do paciente, pois seu preparo educacional envolve prover conforto ao paciente como um todo ${ }^{(16)}$. Como profissionais de saúde, temos contato com pessoas que experimentaram perdas decorrentes de traumas, doenças e deficiências físicas. Por isso, devemos ser responsáveis e sensíveis para buscar alívio para os que estão sofrendo ${ }^{(17)}$.

A lesão por queimaduras resulta em uma das mais graves formas de dor, sendo necessário o uso agressivo de medicação. Os procedimentos de banho, curativo e fisioterapia provocam dor, que é descrita como de curta duração, porém de maior intensidade. Por esta razão, a medicação adequada deve ser administrada antes dos procedimentos, que serão realizados por dias e até semanas ${ }^{(18)}$.

Os profissionais tentam ajustar o dia-adia das atividades às necessidades do paciente, mas isso não parece ser suficiente para alguns. Um exemplo disso está relacionado ao medicamento para alívio da dor a ser administrado antes dos procedimentos de banho e curativo. Nesta Unidade de Queimados, a prescrição desse medicamento é realizada pelo médico, entretanto, cabe ao enfermeiro decidir se administra ou não e avaliar e registrar os efeitos da droga administrada. Outros profissionais de enfermagem, auxiliares e técnicos, também participam dessa avaliação, pois, freqüentemente, são eles que detectam a presença de dor, informam o enfermeiro (que avalia e toma decisões), e que implementam o 
cuidado. Assim, a avaliação da dor em relação aos efeitos da droga administrada depende da sensibilidade e do conhecimento do profissional que, algumas vezes, acredita que a dor é inerente ao procedimento.

Mariana: Eu acho que o paciente portador de queimaduras é um processo doloroso, acho que a gente sente a dor do paciente, muito doloroso, muito sofrido,... dolorido é, tem hora, que é, fatigante assim, você ouvir a pessoa reclamar de dor, dor, dor na sua cabeça, mas você tem que limpar. (Auxiliar de enfermagem)

Beatriz: A gente tem que primeiro cuidar com bastante paciência e cuidar com carinho, dar assistência necessária, banho, curativo e também proteger da dor... (Auxiliar de enfermagem)

Assim, alguns profissionais são sensíveis à dor do paciente, mas, muitas vezes, não conseguem visualizar o seu papel na avaliação dos resultados do cuidado realizado para alívio da dor, nesse caso, do medicamento administrado. Percebem o seu papel no que se refere a cuidar com atenção e com carinho, o que nem sempre é suficiente. Essa situação se repete independentemente do profissional responsável pela assistência, quer seja para enfermeiros como para auxiliares de enfermagem. Os procedimentos têm que ser realizados e estão interiorizados pelos profissionais tanto no que tange à técnica quanto às conseqüências e resultados esperados.

No plantão noturno, a dor aparece em outro contexto porque os procedimentos de banho e curativo não são realizados nesse horário, mas os pacientes solicitam a medicação para atravessar o período noturno sem sentir dor. Pal, Cortiella, Herndon ${ }^{(18)}$ descreveram um tipo de dor no paciente que sofreu queimaduras não relacionado a procedimentos de banho e curativo. Esta dor ocorre quando o paciente está em repouso, ela é constante e é aliviada naturalmente, quando o paciente está deitado em seu leito.

Nos relatos a seguir, observa-se que os profissionais classificam a dor como "verdadeira" ou "não":

Lara: Por exemplo, a gente lida com a dor e cada um tem um tipo de dor, e aí, todo tipo de dor a gente tem que respeitar até que seja verdadeira ou não, a gente respeita porque cada um é um ser humano diferente de outro! (Enfermeira)
Pedro: Muitos pacientes, mesmo conscientes sobre o que tem que ser feito, não querem sentir dor... (Auxiliar de enfermagem)

Diariamente, o paciente é submetido a procedimentos altamente dolorosos, que muitas vezes, necessitariam de uma sedação mais adequada para que pudessem ser realizados. Como por exemplo, o desbridamento durante o curativo. Esse procedimento é traumático para o paciente tanto pelo aspecto da lesão como pela dor que ele sente. O profissional de enfermagem realiza o banho para remoção da pomada do curativo anterior e dos tecidos desvitalizados, isso promove um ambiente que favorece o processo de cicatrização. Apesar de esse processo ser doloroso, ele tem uma finalidade: fazer com que o paciente se recupere da melhor forma. Entretanto, é preciso questionar se a forma como esse procedimento está sendo realizado não implicaria em maior preparo do paciente no que tange a sedação. É um direito do ser humano não querer sentir dor, mas a equipe, muitas vezes, não visualiza o que poderia ser modificado no próprio cuidado, para que a dor fosse evitada ou minimizada.

A ausência de um controle adequado para a dor durante a hospitalização do paciente que sofreu queimaduras gera, não somente uma experiência traumática com efeitos psicológicos, mas também contribui para a presença de problemas físicos subseqüentes nos pacientes que, em razão da dor, não conseguem realizar as atividades de fisioterapia. $\mathrm{O}$ controle da dor deve ser a prioridade durante todas as fases de internação do paciente na unidade de queimados. Pesquisadores sugerem que um protocolo para avaliar e tratar a dor seja desenvolvido de forma que a equipe multidisciplinar enfoque o problema da dor regularmente ${ }^{(19)}$. Entretanto, protocolos dessa natureza devem ser utilizados considerando-se a individualidade do paciente.

No depoimento a seguir, o profissional expõe seus questionamentos a respeito das medicações que estão sendo utilizadas para a sedação do paciente:

\footnotetext{
Júlia: Acho que os médicos tinham que pesquisar medicação que tirasse a dor, nem Nubaim, nem Dolantina, nem Dormonid tiram, essas medicações deixam o paciente desnorteado. É horrível. Eu já tomei e continuei sentindo dor, mas sem conseguir ordenar as idéias. (Auxiliar de enfermagem)
}

As dimensões do cuidado em uma unidade de queimados: um estudo etnográfico 
Elaine Carvalho F.B.Costa Lídia Aparecida Rossi
Apesar desses questionamentos, todo o processo de trabalho já está estabelecido e interiorizado, no que se refere à técnica, pois o que deve ser feito está definido, assim como as suas conseqüências. $\mathrm{Na}$ percepção da equipe, cabe ao paciente ser capaz de lidar melhor com isso e ao profissional tentar ajudálo, dando um tipo de apoio que, algumas vezes, não é eficiente.

Pedro: A gente não pode fazer nada com ele, então você tem que abordar ele por aí ou levando tudo na esportiva ou sendo duro com ele ou sendo brincalhão, sendo mais delicado com ele... (Auxiliar de enfermagem)

Mariana: Tem que respeitar a dor dele, eu sei que ele está com dor, mas ele tem que saber também que eu tenho que limpar para o bem dele, então é uma coisa que vai e volta: eu respeito a dor dele, ele respeita a minha posição de estar limpando, só que isso é um retorno para ele, que o tratamento é dele... (Auxiliar de enfermagem)

A dimensão emocional, além da dimensão física, também engloba as reações dos profissionais frente ao cuidado e está relacionada ao significado atribuído a características dos pacientes como, por exemplo, a idade e a história do acidente. Esses significados são construídos e estruturados socialmente, interiorizados e reproduzidos por meio do habitus e pela ordenação hierárquica existente no campo, que se preocupa em manter o que está estabelecido e não tem interesse na mudança.

Diante dessa situação, os profissionais tentam fazer o que deve ser feito, mas se sentem estressados e vulneráveis diante de determinadas situações, as quais não se sentem preparados para enfrentar como, por exemplo, cuidar das crianças. Os depoimentos a seguir ressaltam o sofrimento do profissional na assistência à criança queimada.

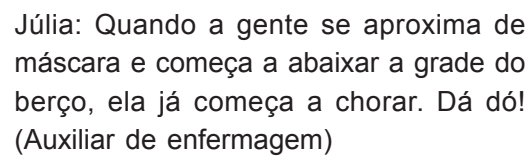

Em um estudo realizado nesta mesma unidade, que teve como objetivo identificar os significados atribuídos pela equipe de enfermagem às manifestações de dor apresentadas pelos pacientes que sofreram queimaduras e identificar as percepções desses paci- entes frente à dor provocada pela queimadura e a assistência de enfermagem prestada nestas situações, os participantes afirmaram que cuidar de crianças é mais estressante do que cuidar de adultos. Relataram que entendem e aceitam as manifestações de dor da criança, o que não ocorre em relação aos adultos que, na opinião deles, deveriam suportar a dor ${ }^{(5)}$. Fato esse também observado neste estudo:

Pedro: [...], agora o que tenho mais dificuldade é com criança. Com criança é mais difícil, mesmo assim a gente não deixa de fazer, tem que fazer. (Auxiliar de enfermagem)

Mariana: É [...], eu não gosto muito de cuidar de criança, eu acho que eu não me sinto bem, principalmente quando tem óbito, eu me apego muito, e é muito sofrimento isso quando é muito pequenininho, eu não gosto de cuidar de criança.. (Auxiliar de enfermagem)

Com o paciente adulto, a percepção é diferente. Para os profissionais, os adultos deveriam suportar a dor e não manifestá-la por meio de choros e gritos. Isto está exemplificado na fala a seguir, que também nos mostra um outro aspecto da relação do profissional com o paciente: a atribuição de culpa pelo acidente:

\footnotetext{
Mariana: [...] eu acho a criança inocente sensível, não tem responsabilidade nenhuma com o que aconteceu com ela [...] $E$ o adulto não, o adulto, na maioria, só se for um acidente, mas na maioria das vezes ele é responsável, ele tem noção do que ele esta fazendo... (Auxiliar de enfermagem)
}

A história do acidente afeta a relação do profissional com o paciente e com a família, principalmente quando o paciente é uma criança, pois o julgamento decorrente de como ocorreu o acidente e das pessoas envolvidas está presente na atitude do profissional, como pode ser observado nos depoimentos a seguir:

Ludmilla: Êh... mãe incompetente, né?! Deixar o carrinho perto do fogão é incompetência, né! (Auxiliar de enfermagem)

Márcia: Eu não sei o que acontece com essas mães. São descuidadas. Essas crianças não tinham que sofrer isso tudo. (Auxiliar de enfermagem) 
A história do acidente e o julgamento dos profissionais estão presentes também como o paciente adulto. O profissional questiona os fatos relatados sobre o acidente e os relaciona com a história de vida do paciente e com seu comportamento durante o tratamento. Esse julgamento também tem implicações para o cuidado.

Ludmilla: Até isso a gente aprendeu a observar, se é tentativa de suicídio ou acidentes, se eles estão mentindo ou não. (Auxiliar de enfermagem)

Gabrielle: Bom para a gente, o que é mais difícil de lidar é com o paciente PQU (rótulo atribuído ao paciente com problemas psiquiátricos), tentativa de suicídio né? Geralmente, abuso que é mais difícil de lidar... (Auxiliar de enfermagem)

Em uma das entrevistas, a auxiliar de enfermagem expõe seu ponto de vista a respeito do paciente envolvido em tentativa de suicídio. Neste aspecto, os valores sociais e a visão de mundo dos profissionais que interagem no cuidado são revelados por meio da maneira como lidam com essa situação.

\begin{abstract}
Mariana: Então, eu acho, quando é paciente tentativa de suicídio ou paciente psiquiátrico existe certo preconceito. Eu acho que é lógico. A pessoa fez porque ela quis, mas ela tem um motivo por trás que a gente não sabe o que é, às vezes a pessoa sofre tanto já com outras coisas chega aqui ainda é, como é que fala? Recebe preconceito, não pode. (Auxiliar de enfermagem).
\end{abstract}

Ao mesmo tempo em que alguns profissionais parecem compreender o problema do paciente, outros parecem entender que a dor deverá ser sentida pelo paciente, pois ele foi o causador do problema. Isso é retratado no depoimento a seguir:

Mariana: Às vezes, as pessoas comentam que: "Ah! Tentativa de suicídio, ele se pôs fogo e depois quer chegar aqui e não sentir dor!". Essa pessoa que se pôs fogo é porque ela está num momento muito difícil da vida dela né, e isso daí da gente ter esses minutos de bobeira que a gente fala pode acontecer com qualquer pessoa, de repente sente um desespero e acaba fazendo uma besteira.... (Auxiliar de enfermagem)

Desse modo, é possível observar que as reações dos profissionais frente ao sofrimen- to e aos fatos que são socialmente reprovados são estruturadas pelo grupo.

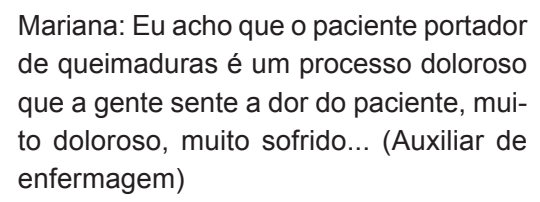

Assim, a dor não passa despercebida e, algumas vezes, o profissional mostra-se sensível a ela. Isso influencia seu relacionamento com o paciente. Esse envolvimento é importante no cuidado, mas deve ser trabalhado e discutido. A compaixão, em alguns casos, pode beneficiar a realização do cuidado, estimulando o profissional a satisfazer as necessidades do paciente. Por outro lado, o excesso de compaixão pode forçar o profissional a bloquear-se emocionalmente, negando como, conseqüência, o aspecto humanístico do cuidado e transformando o paciente em objeto ${ }^{(20)}$.

Cronin $^{(21)}$ investigou a maneira como enfermeiros lidam com suas emoções numa unidade de queimados e afirma que é necessário discutir problemas e situações que são consideradas emocionalmente difíceis para os membros de uma equipe. Concluiu que cada profissional tem diferentes interpretações do significado das emoções e reagem de diferentes formas em uma mesma situação. Outras vezes, da mesma forma como observado nesse estudo, notou que os profissionais expressavam valores e sentimentos diferentes diante das situações, mas eram levados a agir de uma forma que fosse aceita pelo grupo.

A necessidade de apoio psicológico é nítida e deveria ser considerada. É imprescindível a ajuda por meio de um sistema de apoio à equipe, fornecido pela instituição hospitalar, pois os profissionais de enfermagem estão expostos a situações estressantes por serem responsáveis pela assistência ao paciente que sofreu queimaduras e por terem que lidar com seus próprios conflitos e emoções.

Mariana: Então, eu acho que a gente tinha que ter algum tipo assim [...] de batepapo, de [...] a psicóloga estar conversando com a gente, fazer algum trabaIho, não sei que trabalho tem que ser feito. Para você sair daqui mais aliviada. $\mathrm{E}$ [...] porque a gente lida com essas situações, aparentemente você lida bem, mas sempre fica algum resíduo na nossa vida, você não é de pedra, não tem jeito de sair
As dimensões do cuidado em uma unidade de queimados: um estudo etnográfico 
Elaine Carvalho F.B. Costa Lídia Aparecida Rossi daqui sem se envolver com as situações e, às vezes, a gente não tem como resolver, fica uma coisa assim, você se preocupa tanto, pensa tanto e aí o paciente vai embora, você não tem como agir, não tem o que fazer e passa. aí? Aquilo que você sofreu, fica aqui, não fica? Na sua mente, no seu coração. Já machucou e aí? Precisa sarar, precisa trabalhar isso. (Auxiliar de enfermagem)

O suporte psicológico origina-se da discussão regular dos assuntos da unidade. $\mathrm{O}$ apoio mútuo entre os membros da equipe promove senso de união e compreensão de aspectos emocionais relacionados ao cuidado ao paciente que sofreu queimaduras. Com o objetivo de identificar situações estressantes e delinear estratégias para enfrentálas, Sutton ${ }^{(1)}$ ressalta a dificuldade que as instituições têm para atingir níveis de satisfação dos profissionais de saúde e sugere o desenvolvimento de programas de apoio com o intuito de avaliar e satisfazer as necessidades tanto dos profissionais como dos pacientes.

\section{CONSIDERAÇÕES FINAIS}

O tema aqui apresentado focaliza alguns aspectos que estão implicitamente inseridos no processo de cuidado na Unidade de Queimados.

Observa-se que as atividades de banho e curativo influenciam sobremaneira as reações da equipe, levando-a a desenvolver, em algumas situações, uma atitude de firmeza pela responsabilidade do "serviço bem feito" e, em outras, uma atitude de compaixão devido ao sofrimento decorrente desses procedimentos. Porém, essas reações são regidas e

\section{REFERÊNCIAS}

(1) Sutton G. Entry to the burns team: stressors, supports and coping strategies. Burns 1993; 19: $349-51$

(2) Ferreira LA. Construindo o processo que levou o paciente queimado à intercorrência da queimadura. [dissertação] Ribeirão Preto (SP): Escola de Enfermagem de Ribeirão Preto/USP; 1997.

(3) Rossi LA, Braga ECF, Barruffini RCP, Carvalho EC. Childhood burn injuries: circumstances of occurrences and their prevention in Ribeirão Preto, Brazil. Burns 1998; 24: 416-19. controladas pelas leis de funcionamento do contexto social. Cada integrante deste contexto exerce influência e é influenciado por outros, proporcionando, desta forma, a reprodução de um modelo de assistência ao paciente que, na maioria das vezes, não considera sua individualidade.

As relações entre os profissionais da Unidade e as posições que ocupam neste contexto demonstram como o processo de reprodução das práticas e dos comportamentos se desenvolve. Para que o cuidado seja aperfeiçoado, é preciso que haja espaço para a prática crítica e reflexiva, que a rotina seja mantida dentro dos limites nos quais ela é necessária e que todos os aspectos que envolvem o cuidado ao paciente sejam questionados no dia a dia. Para que isso ocorra, é preciso que a estrutura organizacional promova esse espaço e, assim, possibilite a participação crítica dos agentes inseridos neste contexto.

A possibilidade de mudança da estrutura que permeia o sistema de relações do grupo é gradativa e surge do interesse dos agentes pelo crescimento profissional e desenvolvimento de uma assistência de qualidade. Este interesse faz com que os agentes busquem oportunidades para reformulação das leis de funcionamento do campo. Este processo de revolução é bastante complexo e lento, porém fundamental.

É nesse sentido que a compreensão das atitudes e emoções da equipe de enfermagem responsável pelo cuidado ao paciente que sofreu queimaduras traz reflexão e fornece subsídios para que programas educativos e de apoio possam ser implementados
(4) Heindrich G, Perry S, Amand R. Nursing staff attitudes about burn pain, burn rounds. J Burn Care Rehabil 1981;2:259-61.

(5) Rossi LA, Camargo C, Santos CMNM, Barruffini RCP, Carvalho EC. A dor da queimadura: terrível para quem sente, estressante para quem cuida. Rev Lat Am Enferm 2000; 8: 818-26.

(6) Ferreira PJ de O. O cuidar humano/profissional da pessoa que sente dor: virtudes de uma prática que visa o bem. [dissertação] São Paulo (SP): Escola de Enfermagem da USP; 1997. 
(7) Steenkamp WC, Van Der Merwe A. The psychosocial functioning of nurses in a burn unit. Burns 1998; 24: 253-58.

(8) Bourdieu P. Razões práticas - sobre a teoria da ação, Campinas: Papirus; 1996.

(9) Ortiz R, Fernandes F. Pierre Bourdieu - sociologia. São Paulo: Ática; 1994.

(10) Cuche D. A noção de cultura nas ciências sociais. Trad. de Viviane Ribeiro. Bauru: EDUSC; 1999.

(11) Miles MB, Huberman AM. Qualitative data analysis: an expanded sourcebook. London: Sage Publications; 1994.

(12) Flick U. An introduction to qualitative research. London: Sage Publications, 1998.

(13) Germain C. Ethnography: the method. In: Munhall P, Boyd O. Nursing research: a qualitative perspective. New York: Nation League for Nursing Press; 1993. p.145-62.

(14) Artiz CP, Moncrief JA, Pruit BA. Queimaduras. Rio de Janeiro: Interamericana; 1980.

(15) Forest D. The experience of caring. J Adv Nurs 1989;14: 815-23.
(16) Morse JM. Strategies of enduring and the suffering of loss: modes of comfort used by a resilient survivor. Holist Nurs Pract 1995; 9: 38-52.

(17) Morse JM. Responding to the cues of suffering. Health Care Women Int 2000; 21: $1-9$.

(18) Pal SK, Cortiella J, Herndon D. Adjunctive methods of pain control in burns. Burns 1997; 23: 404-12.

(19) Blumenfield M, Schoeps M. Reintegrating the healed burned adult into society: psychological problems and solutions. Clin Plast Surg 1992; 19(3): 599-605.

(20) Morse JM, Mitcham C, Van Der Steen WJ. Compathy or physical empathy: implications for the caregivers relationship. J Med Humanit 1998;19:51-65.

(21) Cronin C. How do nurses deal with their emotions on a burn unit? A hermeneutic inquiry. J Clin Nurs 2001;10(2): 301-2.
As dimensões do cuidado em uma unidade de queimados: um estudo etnográfico 